\title{
MEDIA DISCOURSE IN THE CONTEXT OF VALUES STUDY
}

\author{
Tatiana Prisyazhnyuk ${ }^{1}$, Elena Zilova ${ }^{2}$
}

\begin{abstract}
In the study of mass communication, there has been much debate as to what extent the media can influence the audience. Instead of merely reviewing existing findings in the field, this article aims at searching for some new aspects to the problem. Previously, the study of Media Discourse was mainly restricted to the role of the media in the context of political or social sphere. This research offers to study the issue within a broader multidisciplinary framework involving such macrostructures as society, the mass media, language, and cognition.

The primary objective of the research is to define Media Discourse in the context of the study of values representation. The methods employed in the research are: discourse analysis, linguo-cognitive modeling, componential analysis, and contrastive linguo-cultural analysis. Modern Russian and British media texts were randomly selected for analysis building a corpus of 200 items. In connection with Media Discourse, at least three types of values should be distinguished: discourse values or discourse qualities; values endemic to a particular society, and broadcast by the media in order to cultivate national identity; specific media values generated by certain media, which in many instances can be viewed as "anti-values." The research findings claim that this trend can be observed both in the Russian and British Media Discourse.
\end{abstract}

UDC Classification: 81'42, DOI: http://dx.doi.org/10.12955/cbup.v2.471

Keywords: Media Discourse, fundamental values, national values, transformation of values, anti-values

\section{Introduction}

When referring to the influence of the mass media on the audience, it is usually mentioned that public perception is shaped to a certain extent with the help of media. Van Dijk (1995) stressed the necessity of media study by stating that media power is mainly symbolic and persuasive with the great potential to control readers' and viewers' minds. The evidence gained during the course of study in the Russian and British Media Discourse suggests that certain values are not only disseminated by means of the media, but are transformed as well. This fact exemplifies the interconnection of society, the mass media, language, and cognition, thus, draws our attention to the importance of such studies.

The theoretical framework for the present research is articulated within the multidisciplinary field of sociolinguistics, discourse analysis, and cognitive linguistics. Though the discussions of media influence have been central to many works on mass communication (Van Dijk, 1995, 2009; Bednarek, 2006), the process of values transmission by means of Media Discourse seems to remain among the lesser-studied. So, it is necessary to gain a systematic understanding of the media strategies in values presentation. Thus, the article aims to answer the following questions:

1. What is Media Discourse?

2. What is value from the linguistic point of view?

3. What role does Media Discourse play in the process of values transmission for public consumption?

4. What linguistic mechanisms are employed to aid values dissemination through the media?

\section{Distinctive features of Media Discourse}

A brief conceptual analysis is needed in order to specify the main distinctive features of Media Discourse. In linguistic theory, discourse is often viewed as structure or as process. The followers of the structural approach restrict their observations to what constitutes a unit of discourse: "language above the sentence or above the clause" (Stubbs, 1983). So, discourse analysis is restricted to the search for units of language that demonstrate a relationship that occur in predictable patterns and have

\footnotetext{
${ }^{1}$ Tatiana Prisyazhnyuk, Saratov State University, Russian Federation, prisyazhnjuk_rt@mail.ru

2 Elena Zilova, Saratov State University, Russian Federation, 19elenka80@mail.ru
} 
rules that govern the occurrence of these elements (Roy, 2000). In other fields, discourse is described as "any aspect of language use" (Fasold, 1990), the use of language in speech and writing in order to produce meaning, or as the process of using language to accomplish a purpose or action. Within this perspective, the way language functions to achieve objectives of people's lives is mainly studied (Schiffrin, 1994).

In the context of this study, however, discourse is the "language as it is actually uttered by people engaged in social interaction to accomplish a goal” (Roy, 2000). Media Discourse, in this regard, is a type of institutional discourse (as opposed to personal discourse), which is characterized by a stable system of status relations and social roles, in the sphere of the mass media, that uses language to accomplish specific purposes and to perform certain functions.

Thus, the primary data of the research are the national Russian and British mainstream quality periodicals, youth magazines, TV scripts, and web-pages. In other words, a wide range of materials defined as media-texts. This broad definition of the term "text" agrees with the ideas of Fairclough (2004) who described text as "any actual instance of language in use.” In our case, "language in use” is supplemented with visual image and sound effects. Thus, a media text is a video-verbal text.

The methods employed to aid the accomplishment of the objectives of this research are: discourse analysis, linguo-cognitive modeling, componential analysis, and contrastive linguo-cultural analysis aimed at finding some differences and similarities of the Russian and British representations of the systems of values in the context of Media Discourse. The number of methods employed can be explained by the complexity of the research object.

Media Discourse has its own distinctive features, which can be observed in various media products. A wide array of structural elements, constituting Media Discourse, encompasses both written (printed) and oral (spoken) forms including the press, television, radio, and the internet. This allows further structural subdivision of Media Discourse into genre subgroups.

Media Discourse has two main interconnected objectives, which are to inform and to influence readers and viewers. So, it is also important to single out such functions of Media Discourse as to form public opinion, to bring new information to the audience, to educate, to regulate, to evaluate, to criticize, to publicize, to advertise, and, of course, to entertain. This list of functions is not intended to be exhaustive, only extensive.

These intertwined functions, which in many cases seem to be dialectically opposed, do not affect the consistency of Media Discourse in general. This can be explained by the fact that different functions are only dominant in different genre subgroups: the news media dominant function is to inform; the analytical media dominant functions are to evaluate, to criticize, and to form public opinion); the dominant function of "the media aimed at publicizing" is to bring new information to the masses and to advertise); the dominant function of "the media aimed at entertaining" is to entertain.

Consequently, any media text, viewed as a structural constituent of Media Discourse, can simultaneously inform and influence to a certain extent; thus, it is involved in the process of dissemination of media-specific verbal/non-verbal cognitive items of reality (and values).

\section{Values viewed as constituents of Media Discourse}

The results of researches conducted in the field of the mass media claim that, due to its ubiquitous penetration in everyday life, such phenomena as media-saturated reality and media-affected mentality should be introduced. The latter is defined as the mental/cognitive result of media influence on a person's mind achieved by means of implantation of media-specific verbal/non-verbal cognitive items of reality representation (Rogozina, 2003). So, in this way, people may also acquire new values as part of media-transmitted reality representation. 
There are many definitions of value as this notion is used in different scientific fields. Values are usually defined as goals, which guide human beings in communication or other activities and determine the norms of their behavior. Researchers differentiate between such values as personal and collective, universal, national, cultural, aesthetic, religious, ideological, etc. (Babaeva, 2004).

From the linguistic point of view, values are perceived as concepts, which are contained in a concentrated way a code of norms and regulations are ingrained in culture. As renowned, concept is a mental-cognitive unit of human reasoning. So, human knowledge is organized with the help of such cognitive models.

For example, value "prosperity," which is viewed as a conceptual system, is made of several verbal representatives. Briefly, its core contains the following cognitive elements: "a quiet condition or flow of life," which encompasses "life undisturbed by misfortunes, failures, shock and stress" and "life accompanied by success, good luck." There are four additional layers: "material security," "absence of financial problems, material lacks, troubles," and "well-being”; "happiness" with such properties as "happiness in love," "happiness in family life,” and "mutual love”; "goodness”; "health.”

The values disseminated by Media Discourse are numerous as Media Discourse comprises of various structural elements constituting its integrity. There can be traced values endemic to social, political, and commercial spheres. Verbal representatives of these values are also multi-textual.

It is worthwhile to mention that the study of values in Media Discourse should not be limited only to what is broadcast by Media Discourse. Despite the fact that Media Discourse is a powerful medium for value transmission, it has its own values ingrained in the discourse structure. Such values serve as the distinctive features of Media Discourse and are known as media values that shape the creation of news, as well as other media products.

So, in connection with Media Discourse, we have to distinguish between:

1. media discourse values or discourse qualities;

2. values endemic to a particular society, broadcast by the media (national, cultural values, etc.);

3. values generated by the media and implanted in the minds of the representatives of certain social groups (new media specific values).

Media discourse values or discourse qualities are universal and can be singled out both from the Russian and British regulation documents (Code of Professional Ethics of Russian Journalist [CPERJ], 1995; Editors' Code of Practice [ECP], 2011). It is possible to list several qualities with their verbal representatives: objectivity (fairness, truth, impartiality), accuracy (importance, significance, modernity), newsworthiness, comprehensiveness of information, extensiveness of information, reliability, and legitimacy. The following quotations will suffice to exemplify these points: "Journalist distributes and comments only the information he believes to be true and from trustworthy sources. $\mathrm{He} /$ she does everything possible in order to avoid any harm to anyone by incomplete, incorrect information or intentional concealment of socially important information, or by distribution of deliberately false information” (CPERJ, 1995). "The Press must take care not to publish inaccurate, misleading or distorted information, including pictures” (ECP, 2011).

On the other hand, every ethnic group or community has its own code of norms and values ingrained in its culture and society. By means of linguo-cultural and psycho-linguistic analysis, researchers can single out dominant values of a particular group. According to the survey conducted by YouGov at the request of the Daily Telegraph, the British named "freedom of speech (free speech), politeness, 'fair play,' tolerance” among their national cultural values (King, 2013). Russians consider “family, religion, the Motherland, friendship” as their fundamental national values (Babaeva, 2004). 
The evidence gained during the course of the study of the Russian and British Media Discourse suggests that most mainstream quality papers transmit and accentuate such values in order to cultivate national identity of the audience. Here are some examples: "It violated Haye's right to freedom of speech and freedom of religious belief under the European convention on human rights" (The Telegraph, 2013); "A second senior executive said the industry had already been advised that the proposal that the regulatory body could force newspapers into making apologies it did not agree would be illegal, as it would be contrary to article 10 of the European convention of human rights which protects freedom of speech" (O'Caroll, 2013).

But when we study the values of a certain discourse, as applied to a particular society, culture and language, we find out that discourse values do not represent the whole spectrum of values from that particular ethnic group. For example, prosperity and well-being are universal values, while accuracy is a distinctive value of Media Discourse. Though, they are interconnected, to a certain extent, as one can judge about any society by values of its institutional discourses and vice versa.

\section{The role of Media Discourse in value transmission for specific social groups}

Suffice to say that the media has a powerful influence on public opinion, in many cases, it may even be called "manipulation," though special techniques make it look factual and unbiased. It might be called "propaganda in disguise." Media Discourse has an array of techniques to generate emotional haze and promote certain values. In many cases "new media-specific values" compete or even come into conflict with national values. It should also be mentioned that the transformation of values, which may be considered the trend of the time, in many respects is caused by the media. Researchers speak about transformation and deterioration of fundamental values, which stem from the promotion of "new" values. The most vulnerable group in that respect is young people.

The media for young people and teens, as part of Media Discourse, creates particularly serious concerns. Information on such media is not extensive, but is restricted to particular themes, such as gossips, scandals, interviews with stars and celebrity, new names and styles in music and movies, fashion, make-up, love stories, sex, moneymaking schemes, extreme sports, quizzes, horoscopes, and reality shows.

Upon examining the evidence, the facts do not give any reason for optimism. Using a corpus of 200 Russian and British media texts, we can draw the conclusion that anti-values exist in Media Discourse as well, even though they are disguised as values in the context of media-saturated reality. Among these new media-specific values, which have come into conflict with Russian national values and can be viewed as anti-values, we can name hedonistic belief to "enjoy today, don't think about tomorrow, pleasure is the most important thing in life," even if it contradicts the traditional belief of "life for the sake of future generations," which has always been a characteristic feature of the Russian society.

Unfortunately, modern media for young people and teens often twists and distorts endemic values. Instead, there are such items as immorality, perversion, intolerance, and foul language, which are advertised by certain media institutions as equivalents of such values as freedom, free speech, independence, and maturity. This kind of philosophy is blatantly promoted by popular reality shows, which are abundant on TV channels for young people, both in Russia and the UK.

This situation is quite emblematic of what is happening in modern world. As stated by Leith (2013), "when value is destroyed, anti-value fills the void." Thus, it is crucial to study Media Discourse from the viewpoint of social responsibility and productive linguistics to single out the means used to generate emotional haze and promote certain anti-values. 


\section{Conclusion}

There is no doubt that the media is influential in every aspect of our everyday life and plays a crucial role in shaping people's perception. In this respect, Media Discourse presents an ample opportunity for the study of values. There are at least three approaches to the investigation of values in the context of Media Discourse. Values can be studied as elements representing distinctive features of Media Discourse or its qualities. Within this perspective, we may distinguish objectivity, accuracy, newsworthiness, comprehensiveness of information, extensiveness of information, reliability, legitimacy, etc.

Another approach is connected with the study of national values (endemic to particular culture) transmitted and accentuated in the media in order to cultivate national identity. The research conducted in the field of the Russian and British media suggests that most mainstream quality media propagates such values.

The third group represents media-specific values, generated by certain media, which should also be identified and properly studied. As it has been proven in the research, these media-specific values in many instances come into conflict with national values and turn out to be anti-values. In order to understand what mechanisms are employed to aid anti-values dissemination, one needs to pay detailed attention to the structure, language, and strategies of such types of media.

In terms of further study, we suggest an extended comparative research of the mass media involving the countries representing different cultures, political structures, and systems of values. This will give us the key to naming and understanding universal trends of Media Discourse development.

\section{References}

Babaeva, E. V. (2004). Lingvokulturologicheskie kharakteristiki russkoi i nemetskoi aksiologicheskih kartin mira [Russian and German norm-value picture of the world]. Volgograd, Russia: Volgograd University Press.

Bednarek, M. (2006). Evaluation in Media Discourse. New York, NY: Continuum International Publishing Group.

Code of Professional Ethics of Russian Journalist (1995). Retrieved September 30, 2013, from http://ethicnet.uta.fi/russia/ code_of_professional_ethics_of_russian_journalist

Editors’ Code of Practice (2011). Retrieved September 30, 2013 from http://www.pcc.org.uk/assets/696/Code_of_Practice _2012_A4.pdf

Fairclouth, N. (2004). Analyzing Discourse. Textual analysis for social research. New York, NY: Routledge.

Fasold, R. (1990). The Sociolinguistics of Language. Oxford, UK: Blackwell.

King, A. (2013, May 15) What does it mean to be British? Retrieved from http://www.telegraph.co.uk/news/uknews/ 4196988/What-does-it-mean-to-be-British.html

Leith, J. (2013). The Futuregen Glossary: A collection of definitions for innovation, change and strategy practitioners. Retrieved September 30, 2013, from http://www.jackmartinleith.com/glossary/1

O'Caroll, L. (2013, March 18). Press regulation at risk as newspaper groups refuse to endorse deal. Retrieved from http://www.theguardian.com/media/2013/mar/18/press-regulation-newspaper-groups-refuse-endorse

Rogozina, I. V. (2003). Media kartina mira: kognitivno-semioticheskii aspekt [Media-picture of the world: cognitive-semiotic aspect]. Barnaul, Russia: Barnaul University Press

Roy, C. B. (2000). Interpreting as a Discourse Process. Oxford, UK: Oxford University Press.

Schiffrin, D. (1994). Approaches to discourse. Cambridge, Massachusetts \& Oxford: Blackwell Publishers.

Stubbs, M. (1983). Discourse Analysis: The Sociolinguistic Analysis of Natural Language. Chicago: University of Chicago Press.

The Telegraph (2013, April 12). Ban on homophobic teacher upheld. Retrieved from http://www.telegraph.co.uk/education/ educationnews/9989926/Ban-on-homophobic-teacher-upheld.html

Van Dijk, T. A. (1995). Power and the News Media. In D. L. Paletz (Ed.), Political communication in action: states, institutions, movements, audiences. Cresskill, NJ: Hampton Press.

Van Dijk, T. A. (2009). Society and Discourse. How social contexts control text and talk. Cambridge, UK: Cambridge University Press. 